\title{
The effects of living environment on disaster workers: a one-year longitudinal study
}

\author{
Masanori Nagamine ${ }^{1 *}$ D, Nahoko Harada ${ }^{2}$, Jun Shigemura ${ }^{3}$, Kosuke Dobashi ${ }^{4}$, Makiko Yoshiga $^{5}$, Naoki Esaki ${ }^{6}$, \\ Miyuki Tanaka ${ }^{7}$, Masaaki Tanichi ${ }^{3}$, Aihide Yoshino ${ }^{3}$ and Kunio Shimizu ${ }^{1}$
}

\begin{abstract}
Background: Defense Force workers engaged in disaster relief activities might suffer from strong psychological stress due to the tasks that they had been involved. We evaluated how living environments, work environments, and individual factors psychologically affect those who engaged in disaster relief activities.

Method: Data generated with 1506 personnel engaged in the Great East Japan Earthquake relief activity were analyzed. Those who scored $\geq 25$ points on the Impact of Events Scale-Revised and the Kessler Psychological Distress Scale (K10) were allocated into the high post-traumatic stress response (high-PTSR) group, and the high general psychological distress (high-GPD) group, respectively.

Results: The multiple logistic regression analysis extracted living environment (camping within the shelter sites) as the significant risk factor for both high-PTSR $(\mathrm{OR}=3.39,95 \% \mathrm{Cl} 2.04-5.64, p<0.001)$ and high-GPD $(\mathrm{OR}=3.35,95 \%$ Cl 1.77-6.34, $p<0.001$ ) groups.

Conclusion: It is desirable for disaster workers to have a living environment in which they can keep an appropriate distance from the victims.

Keywords: Disaster workers, Great East Japan Earthquake, Post-traumatic stress response, Psychological distress, Risk factors, Living environment
\end{abstract}

\section{Background}

Psychological impacts on disaster workers have been getting a lot more attention in the past decades [1]. Disaster workers are potentially exposed to severe work environments, inhumane situations, and overwhelming emotional reactions from victims. The concepts of secondary traumatic stress, compassion fatigue [2], and vicarious traumatization [3] have been used to describe psychological burdens in social workers. These psychological impacts can trigger various reactions, including depression and anxiety disorder, in addition to stressrelated disorders, such as acute and post-traumatic stress disorder (PTSD) [4]. A recent meta-analysis on disaster relief workers reported that $10 \%$ of the workers

\footnotetext{
* Correspondence: nagaminemasanori@gmail.com

${ }^{1}$ Division of Behavioral Science, National Defense Medical College Research

Institute, Saitama, Japan

Full list of author information is available at the end of the article
}

experience PTSD [5], indicating the seriousness of a psychologically traumatic experience. Young age, being single, previous experiences with natural disasters, poor social support, low educational level, and non-affiliated volunteer status are identified demographic risk factors [4-10]. On the other hand, maintaining professional distance with victims [11], and avoiding excessive empathy and identification [12-14], are reported as mitigating factors. Therefore, the living environment of disaster workers, such as staying on the same premises with the disaster victims, might increase the risk of psychological impacts; however, no study has yet investigated these issues. From the point of view of health management in the disaster, empirical research into such issues is urgently needed. This study is the first to evaluate how living and work environments, as well as individual factors, psychologically affect disaster relief workers. 


\section{Method}

\section{The Great East Japan earthquake}

On 11 Mar 2011, Tohoku district of Japan was struck by a 9.0 magnitude earthquake. This triggered three-fold disasters consisting of earthquakes, tsunamis, and radiation leakage, which resulted in at least 18,000 deaths and missing persons [15]. Immediately after the earthquake occurred, the Japanese government decided to send more than 100,000 Self-Defense Force members to the stricken areas [16].

\section{Study participants}

Approximately 2400 Japan Ground Self-Defense Force (JGSDF) members from the Northern Kyushu region, over $1500 \mathrm{~km}$ away from the afflicted areas, were dispatched to Kesennuma City and Minamisanriku Town in Miyagi Prefecture, which were severely affected by the tsunami. Most of the members departed from their home garrisons on 12 March, and engaged in search and rescue for missing persons until 14 May. After returning to their home garrisons, the mental health status of the troop members were evaluated at 1, 6, and 12 months post-mission completion. We excluded the data of those who could not complete this questionnaire because of relocation or other mission and those who had more than three missing demographic variables. The responses of 1506 members were used in the final analysis.

\section{Living and working environment of disaster workers}

The troops were based in two different types of camps: camps remotely located from the affected area (JGSDF facility for field exercise; approximately $80 \mathrm{~km}$ away from the working area) and camps located in the affected area such as the track fields of schools that were converted to shelters for disaster victims. Since there were insufficient places in the latter camps, some troop members shared their premises with the disaster victims. Due to organizational strict discipline, the members were ordered to refrain from smoking cigarettes and avoid casual conversations in the camps because of their exposure to the public eye.

The troops engaged in search and rescue mission experienced frequent aftershocks. During their activity, there were 659 aftershocks with magnitudes greater than 5.0 [17], and the daily mean temperature ranged from -1.4 to $15.9{ }^{\circ} \mathrm{C}$ [18]. Moreover, almost all facilities of fishery and marine product processing, the main industry of the coastal regions, were absolutely destroyed; rotten fish and its product diffused foul smells that produced non-life threatening but disturbing environments for people [19]. Under such harsh conditions, JGSDF members discovered 521 bodies in this region; most of whom drowned. These included children's bodies and very badly damaged bodies.

\section{Psychological evaluation}

The survey was conducted by JGSDF clinical psychologists at 1,6 , and 12 months post-mission completion. The Japanese versions of the Impact of Events Scale-Revised (IES-R) [20] and the Kessler Psychological Distress Scale (K10) [21] were used for the psychological evaluation scales. The IES- $\mathrm{R}$ is a 22-item self-administered questionnaire used to evaluate post-traumatic stress response (PTSR). It comprises three major PTSD symptoms as subscales: intrusion, avoidance, and hyperarousal [22]. According to a previous report [20], those scoring 25 points or higher were referred to as the high-PTSR group.

The K10 is a ten-item self-administered questionnaire developed by Kessler [23]. It is based on the Item Response Theory and is widely used as a tool for evaluating general psychological distress (GPD) [24, 25]. This measure uses a 24/25-point cutoff value as a screening test for psychological illnesses [26]. As such, those scoring 25 points or higher were considered to be the high-GPD group.

In addition to the two psychological measurements, their living environment factors (camping with only troop members or camping in an environment with disaster victims), working environment factors (dispatch period and whether or not they were exposed to corpses), and sociodemographic factors (age, gender, and rank) were investigated as independent variables.

\section{Statistical analyses}

Regarding the collected data on IES-R and K10, no data showed normality or equal variance; therefore, nonparametric tests were conducted for the chronological analyses (Friedman test and Cochran's Q test) and univariate analyses (Kruskal-Wallis test for age and Mann-Whitney $U$ test for others) on these measures. Bonferroni correction was used for multiple comparisons. Finally, multiple logistic regression analyses were conducted to investigate factors related to the high-risk groups measured by IES-R and K10. In the analyses, those who scored $\geq 25$ on IES-R and $\mathrm{K} 10$ at least once during the research period were allocated into high-PTSR group $(N=71)$ and high-GPD group $(N=43)$, respectively. Since we required at least 10 events of these outcome measures per variable to avoid an overfit model on logistic regression analyses [27], factors that showed at least one or more $p$ value of $<0.2$ in the univariate analysis were designated as independent variables. We used the forced entry method and the significance level for the tests was set as $p<0.05$. IBM SPSS Statistics version 22 was used for the statistical tests.

\section{Results}

Participants' characteristics

Table 1 shows the participants' characteristics. About two-thirds $(67.8 \%)$ of the participants were dispatched 
Table 1 Participants' characteristics and the results of univariate analyses for each attribute

\begin{tabular}{|c|c|c|c|c|c|c|c|c|c|c|c|c|c|c|c|c|c|c|c|c|}
\hline & \multirow[b]{3}{*}{ N } & \multirow[b]{3}{*}{$\%$} & \multicolumn{9}{|l|}{ IES-R } & \multicolumn{9}{|l|}{ K10 } \\
\hline & & & \multicolumn{3}{|c|}{1 month later } & \multicolumn{3}{|c|}{6 months later } & \multicolumn{3}{|c|}{12 months later } & \multicolumn{3}{|c|}{1 month later } & \multicolumn{3}{|c|}{6 months later } & \multicolumn{3}{|c|}{12 months later } \\
\hline & & & Mean & s.d. & $p$ value & Mean & s.d. & $p$ value & Mean & s.d. & $p$ value & Mean & s.d. & $p$ value & Mean & s.d. & $p$ value & Mean & s.d. & $p$ value \\
\hline \multicolumn{21}{|l|}{ Age } \\
\hline$<30$ & 711 & 47.2 & 6.6 & 8.3 & 0.42 & 3.3 & 4.9 & 0.77 & 2.8 & 4.4 & 0.23 & 13.0 & 4.7 & 0.24 & 11.1 & 2.7 & 0.43 & 11.0 & 2.4 & 0.55 \\
\hline 30 to 39 & 311 & 20.7 & 5.8 & 7.0 & & 2.9 & 4.6 & & 2.8 & 4.5 & & 12.5 & 3.4 & & 10.7 & 2.0 & & 11.0 & 2.2 & \\
\hline$\geq 40$ & 484 & 32.1 & 5.9 & 7.3 & & 3.1 & 4.4 & & 3.2 & 5.1 & & 12.3 & 3.7 & & 11.1 & 2.4 & & 11.2 & 2.5 & \\
\hline \multicolumn{21}{|l|}{ Gender } \\
\hline Male & 1485 & 98.6 & 6.2 & 7.7 & 0.18 & 3.1 & 4.7 & 0.72 & 2.9 & 4.7 & 0.14 & 12.6 & 4.2 & 0.81 & 11.0 & 2.5 & 0.45 & 11.1 & 2.4 & 0.56 \\
\hline Female & 21 & 1.4 & 4.3 & 6.7 & & 3.7 & 5.0 & & 3.3 & 3.5 & & 12.6 & 4.0 & & 11.0 & 3.1 & & 11.1 & 1.9 & \\
\hline \multicolumn{21}{|l|}{ Rank } \\
\hline Officer & 75 & 5.0 & 5.3 & 6.5 & 0.43 & 4.2 & 5.9 & 0.15 & 3.5 & 5.6 & 0.30 & 13.3 & 5.0 & 0.28 & 11.6 & 2.9 & 0.09 & 11.3 & 2.4 & 0.10 \\
\hline Private/Sergeant & 1431 & 95.0 & 6.3 & 7.8 & & 3.1 & 4.6 & & 2.9 & 4.6 & & 12.6 & 4.1 & & 11.0 & 2.5 & & 11.0 & 2.4 & \\
\hline \multicolumn{21}{|l|}{ Dispatch period } \\
\hline$<1$ month & 485 & 32.2 & 5.8 & 7.6 & $<0.05$ & 2.8 & 4.3 & $<0.05$ & 2.9 & 4.6 & 0.64 & 12.4 & 4.0 & $<0.05$ & 10.8 & 2.2 & $<0.01$ & 11.1 & 2.2 & $<0.05$ \\
\hline 1 to 3 months & 1021 & 67.8 & 6.4 & 7.8 & & 3.3 & 4.8 & & 3.0 & 4.7 & & 12.8 & 4.2 & & 11.1 & 2.6 & & 11.0 & 2.5 & \\
\hline \multicolumn{21}{|l|}{ Exposure to corpses } \\
\hline Present & 1030 & 68.4 & 6.8 & 7.9 & $<0.001$ & 3.4 & 4.8 & $<0.001$ & 3.0 & 4.8 & 0.19 & 12.7 & 4.3 & 0.41 & 11.1 & 2.6 & 0.41 & 11.0 & 2.3 & 0.07 \\
\hline Not present & 476 & 31.6 & 5.0 & 7.1 & & 2.6 & 4.3 & & 2.8 & 4.4 & & 12.5 & 3.9 & & 11.0 & 2.3 & & 11.2 & 2.6 & \\
\hline \multicolumn{21}{|l|}{ Living environment } \\
\hline Only with troop members & 1253 & 83.2 & 5.7 & 7.3 & $<0.001$ & 2.9 & 4.2 & $<0.01$ & 2.7 & 4.4 & $<0.001$ & 12.4 & 3.9 & $<0.001$ & 10.9 & 2.1 & $<0.001$ & 11.0 & 2.2 & 0.08 \\
\hline Sharing the premises with the victims & 253 & 16.8 & 8.9 & 9.3 & & 4.2 & 6.5 & & 4.1 & 5.8 & & 13.8 & 5.3 & & 11.9 & 3.8 & & 11.4 & 3.1 & \\
\hline
\end{tabular}

IES-R Impact of Event Scale-Revised, K10 Kessler Psychological Distress Scale Statictics: Kruskal-Wallis test for age and Mann-Whitney $U$ test for others 
for 1 to 3 months, with the rest being dispatched for less than 1 month. Approximately $70 \%$ of the troop members were exposed to corpses. While most of the troop members were living in an environment only with other members, some of the members $(16.8 \%)$ were sharing the same premises with the disaster victims.

\section{Chronological data analyses on IES-R and K10}

The chronological data of mean IES-R and K10 scores for all participants is shown in Table 2. A significant correlation was seen between the IES-R and K10 scores for all measurement periods (Spearman's rank correlation test; 1 month: $r=0.614, p<0.001,6$ months: $r=0.484, p<0.001$, 12 months: $r=0.456, p<0.001)$. All the IES-R related scores (total, intrusion, avoidance, hyperarousal, ratio of high-PTSR group) at 6 and 12 months significantly decreased from the score at 1 month (Friedman and Cochran's Q test, multiple comparisons with Bonferroni correction: 1 month $>6$ months, 12 months, $p<0.001$ ).

Similar to IES-R, K10 scores and ratio of high-GPD group significantly decreased from 1 to 6 months and 12 months post-mission (Friedman and Cochran's Q test, multiple comparisons with Bonferroni correction: 1 month $>6$ months, 12 months, $p<0.001$ ).

\section{Univariate analyses}

The results of the univariate analyses for each participant's attributes are also shown in Table 1 . No significant correlations were found regarding age, gender, or rank for either IES-R or K10. Concerning the dispatch period, a significant difference was found in most of the psychological measures except for the IES-R conducted at 12 months. The group that experienced longer dispatch periods had a significantly high score. The group with exposure to corpses had significantly higher IES-R scores at 1 and 6 months compared to the group without exposure. Concerning living environment, significant differences were seen for most of the psychological measures except the K10 score at 12 months.
The group that shared the same premises with the disaster victims had significantly higher scores than the group that lived with only dispatched troop members.

\section{Multiple logistic regression analyses}

Table 3 shows the multiple logistic regression analysis results. In the univariate analysis, most of the independent variables showed at least one or more $p$ value of $<0.2$ except for age on both IES-R and K10, and gender on K10. Therefore, age was excluded as an independent variable in the multiple logistic regression analysis for High-PTSR and age and gender in the analysis for High-GPD.

For both the high-PTSR and GPD groups, living environment was extracted as the significant risk factor. The group sharing premises with the disaster victims was 3.39 times more likely to be in the high-PTSR and 3.35 times in the high-GPD groups than those who camped with only troop members.

\section{Discussion}

We examined the psychological effects of living environment factors, working environment factors, and individual factors on JGSDF troop members who engaged in disaster relief activities following the 2011 Great East Japan Earthquake. Dispatched troop members who shared the same premises as the disaster victims were 3.4 times more likely to be in the high-PTSR and GPD groups compared to those who lived with only dispatched troop members. Tasks that involved the handling of corpses [7, 8, 12-14, 28-30] and long-term relief activities $[9,31]$ have been reported to have large psychological impacts, but this study did not indicate the same results of previous studies. These results imply that not direct but indirect traumatic exposure through relationships with disaster victims could have greater influence on the mental health of disaster workers.

Table 2 Chronological data analyses on IES-R and K10

\begin{tabular}{|c|c|c|c|c|}
\hline & 1 month & 6 months & 12 months & $P$ value \\
\hline IES-R total, mean (s.d.) & $6.2(7.7)$ & $3.1(4.7)$ & $2.9(4.7)$ & $<0.001^{\mathrm{c}}$ \\
\hline IES-R intrusion, mean (s.d.) & $2.4(3.1)$ & $1.3(2.0)$ & $1.2(1.9)$ & $<0.001^{c}$ \\
\hline IES-R avoidance, mean (s.d.) & $2.3(3.6)$ & $1.1(2.3)$ & $1.0(2.2)$ & $<0.001^{c}$ \\
\hline IES-R hyperarousal, mean (s.d.) & $1.5(2.3)$ & $0.7(1.5)$ & $0.7(1.4)$ & $<0.001^{c}$ \\
\hline High-PTSR ${ }^{a}$ group, $n(\%)$ & $56(3.7)$ & $12(0.8)$ & $11(0.7)$ & $<0.001^{\mathrm{d}}$ \\
\hline K10, mean (s.d.) & $12.6(4.2)$ & $11.0(2.5)$ & $11.1(2.4)$ & $<0.001^{c}$ \\
\hline High-GPD ${ }^{\mathrm{b}}$ group, $n(\%)$ & $33(2.2)$ & $8(0.5)$ & $7(0.5)$ & $<0.001^{d}$ \\
\hline
\end{tabular}

IES-R Impact of Event Scale-Revised, PTSR post-traumatic stress response, K10 Kessler Psychological Distress Scale, GPD general psychological distress

${ }^{\text {aD }}$ Defined according to the Japanese version of the Impact of Events Scale-Revised $(\geq 25)$

${ }^{b}$ Defined according to the Japanese version of the Kessler Psychological Distress Scale $(\geq 25)$

${ }^{\mathrm{C}}$ Friedman test, Multiple comparisons with Bonferroni correction: 1 month $>6$ months, 12 months, $p<0.001$

dCochran's Q test, Multiple comparisons with Bonferroni correction: 1 month $>6$ months, 12 months, $p<0.001$ 
Table 3 Results of multiple logistic regression analyses

\begin{tabular}{|c|c|c|c|c|c|c|c|}
\hline & & Reference & $\beta$ & s.e. & Adjusted OR & $95 \% \mathrm{Cl}$ & $P$ value \\
\hline \multicolumn{8}{|l|}{ High-PTSR ${ }^{a}$} \\
\hline Gender & Female & (Male) & 0.13 & 1.05 & 1.13 & $0.15-8.83$ & 0.90 \\
\hline Rank & Officer & (Private/Sergeant) & 0.30 & 0.54 & 1.35 & $0.47-3.86$ & 0.57 \\
\hline Dispatch period & 1 to 3 months & (<1 month) & -0.32 & 0.27 & 0.73 & $0.43-1.22$ & 0.23 \\
\hline Exposure to corpses & Present & (Not present) & 0.21 & 0.28 & 1.23 & $0.71-2.15$ & 0.47 \\
\hline Living environment & Sharing the premises with the victims & (Only with troop members) & 1.22 & 0.26 & 3.39 & $2.04-5.64$ & $<0.001$ \\
\hline \multicolumn{8}{|l|}{ High-GPD ${ }^{b}$} \\
\hline Rank & Officer & (Private/Sergeant) & 0.53 & 0.62 & 1.69 & $0.50-5.69$ & 0.40 \\
\hline Dispatch period & 1 to 3 months & (<1 month) & 0.33 & 0.38 & 1.39 & $0.66-2.90$ & 0.38 \\
\hline Exposure to corpses & Present & (Not present) & 0.00 & 0.36 & 1.00 & $0.50-2.00$ & 0.99 \\
\hline Living environment & Sharing the premises with the victims & (Only with troop members) & 1.21 & 0.33 & 3.35 & $1.77-6.34$ & $<0.001$ \\
\hline
\end{tabular}

PTSR post-traumatic stress response, GPD general psychological distress, OR odds ratio

${ }^{a}$ Defined as those who scored $\geq 25$ on the Japanese version of the Impact of Events Scale-Revised at least once during the research period ( $N=71$ )

${ }^{b}$ Defined as those who scored $\geq 25$ on the Japanese version of the Kessler Psychological Distress Scale at least once during the research period ( $N=43$ )

The effects of living environment on disaster workers

Our results suggest that living environment was the most significant risk factor to participants' post-disaster mental health in particular in this study. To our knowledge, no other study has uncovered such a result. Disaster relief workers potentially experience secondary trauma through their activities. Their outcomes have been reported in many studies in relation to PTSD [5, 32]. Ursano and colleagues have shown the importance of "identification with disaster victims" as a mechanism by which relief workers experience secondary trauma [14]. Cetin and others also reported results that support this finding [12] and warned against excessive identification with disaster victims.

Work-related trauma exposure has been mentioned in various professions. A study on emergency medical personnel reported the importance of having sympathy while maintaining emotional distance as a coping mechanism [33]. In a review of caregivers of torture victims, Pross discussed the importance of keeping a balance between an appropriate professional distance and empathy [11]. In our study, the troop members who lived on the same premises with the disaster victims had many chances of coming into contact with them even after they returned from work. This suggests that they were at a higher risk of experiencing excessive empathy and identification, and had great difficulty keeping their emotional distance from the victims. As a result, living environment may be the largest risk factor for both high-PTSR and GPD.

There are other possible effects of sharing living quarters with victims. In order to maintain the psychological health of disaster workers, the importance of self-care, including obtaining sufficient rest, engaging in non-work activities such as sports, and prioritizing relaxation has been advocated [11, 34]. However, in an environment where they are under the gaze of the victims, the relief workers were probably unable to relax enough even when their work was done for the day. Disaster workers under such conditions might have difficulties in relieving their stress.

\section{Possible factors that reduced psychological effects on disaster workers}

Our results showed that less than $1 \%$ of the participants were in the high-PTSR/GPD groups at 12 months, despite the devastating magnitude of the disaster and exposure to corpses. Meta-analytic studies on past disaster relief activities reported that the PTSD prevalence rate was approximately $10 \%$ [5]. Although our study is not directly comparable to these studies, our results show extremely little lasting psychological impact. We propose three possible explanations for this trend.

Firstly, JGSDF members received high praise and much media appreciation for their efforts in the Great East Japan Earthquake [35], and this experience might have mitigated the negative psychological impacts of the experience [16]. In a study of firefighters who responded to the 1995 Great Hanshin Earthquakes, Kato and colleagues stated that "giving sufficient social praise and support toward disaster workers' activities is extremely significant in reducing the psychological impacts" [36].

Second, this study's participants were troop members deployed outside of the affected areas and were not residing in the disaster areas. Past reports have shown that those dispatched to provide support from within the afflicted areas had significantly more traumatic reactions compared to those dispatched from outside the afflicted areas [36].

Third, a stronger motivation for the personnel's mission might be associated with their lower psychological responses. The Great East Japan Earthquake 
caused unprecedented damage to Japan, and resulted in the largest scale disaster dispatch ever for the JGSDF. Strong morale and a sense of meaningful mission were implied in many statements made by several troop members who engaged in these activities, such as, "I am a troop member for occasions like this" [37]. Feelings of strong morale and a sense of meaningful mission can increase resilience and maintain mental health among relief workers [38, 39]. These factors may have reduced the emotional impacts felt by the troops, although we were unable to objectively evaluate this hypothesis. Future studies are needed to conduct a quantitative analysis of the effects of strong morale and a sense of mission.

\section{Limitations}

Our longitudinal study has several limitations. First, although our results suggest the importance of living environment on disaster workers, we investigated whether they have stayed only with troop members or have been sharing the premises with the victims. Therefore, detailed off-hours exposures to traumatic event (e.g. to what extent they have contact disaster victims or witnessed their hardship) were neither assessed nor quantified. Similarly, we evaluated whether or not they have exposed to dead bodies and have not quantified traumatic exposures during their on-duty task assignments (e.g. numbers of bodies, or numbers of hours of exposure to bodies).

Second, this study does not represent all troops engaged in Great East Japan Earthquake or other disaster relief activities. The participants' psychological impacts were much less severe compared to those in studies of other disasters. This trend can be attributed to various reasons. This study employs a registered questionnaire, which has been reported to influence participants to conceal their symptoms, as compared to an anonymous questionnaire [40]. Furthermore, the Japanese sociocultural background strongly stigmatizes the expression of emotional suffering [41]. Thus, there is a great possibility that the troop members' psychological impacts are underreported in this study.

Finally, this study did not examine other stress-related factors, such as marital status, medical history, or major life events. Further study including such information is needed to obtain more rigorous mental health effects of these factors on disaster workers.

\section{Conclusion}

Our findings demonstrated that the living environment of disaster relief workers is associated with their adverse mental health. This result has significant safety implications for planners of disaster relief activities. Past reports on disaster relief activities mainly focused on work details and individual factors as the risk factors with the most psychological impact. Our results, in addition to this, suggest the importance of separating disaster relief workers' living environment from that of the victims. This process might be helpful for maintaining an emotional distance from disaster victims, and to avoid excessive empathy and identification with victims. Independence from these environment would facilitate workers to perform sufficient self-care, which is potentially effective for the prevention of adverse mental health.

Situations that increase the risk of secondary trauma are not limited to disaster relief activities but also humanitarian aid activities, including medical and welfare activities. Further studies concerning secondary trauma need to be accumulated in order to safely manage the mental health of the people who engage in such activities.

\section{Abbreviations \\ GPD: General psychological distress; IES-R: Impact of Events Scale-Revised; JGSDF: Japan Ground Self-Defense Force; K10: Kessler Psychological Distress Scale; PTSD: Post-traumatic stress disorder; PTSR: Post-traumatic stress response}

\section{Acknowledgements \\ We wish to thank all the participants, medical staff of JGSDF, and Miki Kai who} supported us at the beginning of this research.

\section{Funding}

This work was supported by the Japanese Society for the Promotion of Science KAKENHI Grant Number 26461779.

\section{Availability of data and materials}

Data supporting the findings is available upon request. Please contact the corresponding author of this paper, Masanori Nagamine

(nagaminemasanori@gmail.com), for data availability.

\section{Authors' contributions}

$M N$, conceived and designed the study. MN, KD, MY, NE and MT were involved in the acquisition and analysis of the data, and all authors participated in the interpretation of data for the work. MN drafted the manuscript, and all authors contributed to critically revising the paper. Finally, all authors read and approved the final manuscript.

\section{Competing interests}

The authors declare that they have no competing interests.

\section{Consent for publication}

Not applicable.

\section{Ethics approval and consent to participate}

The Ethics Committee of the Japan Self-Defense Force Fukuoka Hospital approved this study on 21 Mar 2013. Since this survey was conducted as part of a mandatory occupational health program to all the dispatched members of the JGSDF, all the identifiable variables were deleted prior to the analysis.

\footnotetext{
Author details

${ }^{1}$ Division of Behavioral Science, National Defense Medical College Research Institute, Saitama, Japan. ${ }^{2}$ Department of Nursing Science of Community Health Care System, Tohoku University School of Health Sciences, Miyagi, Japan. ${ }^{3}$ Department of Psychiatry, National Defense Medical College, Saitama, Japan. ${ }^{4}$ Camp Kokura, Japan Ground Self-Defense Force, Fukuoka, Japan. ${ }^{5} \mathrm{Camp}$ Beppu, Japan Ground Self-Defense Force, Oita, Japan. ${ }^{6} \mathrm{Camp}$ Kurume, Japan Ground Self-Defense Force, Fukuoka, Japan. ${ }^{7}$ Camp Omura, Japan Ground Self-Defense Force, Nagasaki, Japan.
}

Received: 30 May 2016 Accepted: 4 October 2016 Published online: 21 October 2016 


\section{References}

1. Benedek DM, Fullerton C, Ursano RJ. First responders: mental health consequences of natural and human-made disasters for public health and public safety workers. Annu Rev Public Health. 2007;28:55-68.

2. Figley CR. Compassion fatigue as secondary traumatic stress disorder: an ovenview. In: Figley CR, editor. Compassion fatigue: coping with secondary traumatic stress disorder in those who treat the trumatized. Routledge; 1995. p. 1-20

3. McCann IL, Pearlman LA. Vicarious traumatization: a framework for understanding the psychological effects of working with victims. J Trauma Stress. 1990;3(1):131-49.

4. Fullerton CS, Ursano RJ, Wang L. Acute stress disorder, posttraumatic stress disorder, and depression in disaster or rescue workers. Am J Psychiatry. 2004;161(8):1370-6.

5. Berger W, Coutinho ES, Figueira I, Marques-Portella C, Luz MP, Neylan TC, et al. Rescuers at risk: a systematic review and meta-regression analysis of the worldwide current prevalence and correlates of PTSD in rescue workers. Soc Psychiatry Psychiatr Epidemiol. 2012;47(6):1001-11.

6. Alvarez J, Hunt M. Risk and resilience in canine search and rescue handlers after 9/11. J Trauma Stress. 2005:18(5):497-505.

7. Jones DR. Secondary disaster victims: the emotional effects of recovering and identifying human remains. Am J Psychiatry. 1985;142(3):303-7.

8. McCarroll JE, Fullerton CS, Ursano RJ, Hermsen JM. Posttraumatic stress symptoms following forensic dental identification: Mt. Carmel, Waco, Texas. Am J Psychiatry. 1996;153(6):778-82

9. Perrin MA, DiGrande L, Wheeler K, Thorpe L, Farfel M, Brackbill R. Differences in PTSD prevalence and associated risk factors among World Trade Center disaster rescue and recovery workers. Am J Psychiatry. 2007;164(9):1385-94.

10. Witteveen AB, Bramsen I, Twisk JW, Huizink AC, Slottje P, Smid T, et al. Psychological distress of rescue workers eight and one-half years after professional involvement in the Amsterdam air disaster. J Nerv Ment Dis. 2007:195(1):31-40.

11. Pross C. Burnout, vicarious traumatization and its prevention. Torture : quarterly journal on rehabilitation of torture victims and prevention of torture. 2006;16(1):1-9.

12. Cetin M, Kose S, Ebrinc S, Yigit S, Elhai JD, Basoglu C. Identification and posttraumatic stress disorder symptoms in rescue workers in the Marmara, Turkey, earthquake. J Trauma Stress. 2005;18(5):485-9.

13. Fullerton CS, McCarroll JE, Ursano RJ, Wright KM. Psychological responses of rescue workers: fire fighters and trauma. Am J Orthopsychiatry. 1992;62(3):371-8.

14. Ursano RJ, Fullerton CS, Vance K, Kao TC. Posttraumatic stress disorder and identification in disaster workers. Am J Psychiatry. 1999;156(3):353-9.

15. Emergency Disaster Countermeasures Headquarters. Damage Situation and Police Countermeasures associated with 2011 Tohoku district - off the Pacific Ocean Earthquake. National Police Agency of Japan; 2016. http:// www.npa.go.jp/archive/keibi/biki/higaijokyo_e.pdf

16. Dobashi K, Nagamine M, Shigemura J, Tsunoda T, Shimizu K, Yoshino A, et al. Psychological effects of disaster relief activities on Japan Ground SelfDefense Force personnel following the 2011 Great East Japan Earthquake. Psychiatry. 2014;77(2):190-8.

17. Japan Meteorological Agency. The number of aftershocks with magnitude greater than five after Great East Japan Earthquake. Japan Meteorological Agency; 2011. http://www.data.jma.go.jp/svd/egev/data/2011_03_11_ tohoku/aftershock/

18. Japan Meteorological Agency. The daily mean temperature in Kesennuma City. Japan Meteorological Agency; 2011. http://www.data.jma.go.jp/obd/ stats/etrn/view/daily_a1.php?prec_no=34\&block_no=0242\&year= $2011 \&$ month $=03 \&$ day $=\& v i e w=p 1$

19. Kawabata S. 50,000 tons of rotten fish diffuse foul smell. The Asahi Shimbun Company; 2011. http://www.asahi.com/special/10005/TKY201106040151.html

20. Asukai N, Kato H, Kawamura N, Kim Y, Yamamoto K, Kishimoto J, et al. Reliability and validity of the Japanese-language version of the impact of event scale-revised (IES-R-J): four studies of different traumatic events. J Nerv Ment Dis. 2002;190(3):175-82.

21. Furukawa $T A$, Kawakami $N$, Saitoh $M$, Ono $Y$, Nakane $Y$, Nakamura $Y$, et al. The performance of the Japanese version of the $K 6$ and $K 10$ in the World Mental Health Survey Japan. Int J Methods Psychiatr Res. 2008; 17(3):152-8

22. Weiss DS, Marmar CR. The impact of event scale-revised. The Guilford Press; 1997

23. Kessler RC, Andrews G, Colpe L, Hiripi E, Mroczek DK, Normand SL, et al. Short screening scales to monitor population prevalences and trends in non-specific psychological distress. Psychol Med. 2002;32(6):959-76.

24. Andrews G, Slade T. Interpreting scores on the Kessler Psychological Distress Scale (K10). Aust N Z J Public Health. 2001;25(6):494-7.
25. Furukawa TA, Kessler RC, Slade T, Andrews G. The performance of the K6 and K10 screening scales for psychological distress in the Australian National Survey of Mental Health and Well-Being. Psychol Med. 2003;33(2):357-62.

26. Cornelius BL, Groothoff JW, van der Klink JJ, Brouwer S. The performance of the K10, K6 and GHQ-12 to screen for present state DSM-IV disorders among disability claimants. BMC Public Health. 2013;13:128.

27. Stoltzfus JC. Logistic regression: a brief primer. Acad Emerg Med. 2011;18(10):1099-104.

28. Leffler CT, Dembert ML. Posttraumatic stress symptoms among U.S. navy divers recovering TWA flight 800. J Nerv Ment Dis. 1998;186(9):574-7.

29. McCarroll JE, Ursano RJ, Fullerton CS. Symptoms of PTSD following recovery of war dead: 13-15-month follow-up. Am J Psychiatry. 1995;152(6):939-41.

30. McCarroll JE, Ursano RJ, Fullerton CS, Liu X, Lundy A. Somatic symptoms in Gulf War mortuary workers. Psychosom Med. 2002;64(1):29-33.

31. North CS, Tivis L, McMillen JC, Pfefferbaum B, Cox J, Spitznagel EL, et al. Coping, functioning, and adjustment of rescue workers after the Oklahoma City bombing. J Trauma Stress. 2002;15(3):171-5.

32. Alexander DA, Klein $\mathrm{S}$. First responders after disasters: a review of stress reactions, at-risk, vulnerability, and resilience factors. Prehosp Disaster Med. 2009;24(2):87-94

33. Regehr C, Goldberg G, Hughes J. Exposure to human tragedy, empathy, and trauma in ambulance paramedics. Am J Orthopsychiatry. 2002;72(4):505-13.

34. Rourke MT. Compassion fatigue in pediatric palliative care providers. Pediatr Clin N Am. 2007:54(5):631-44. X.

35. Martin A. Military flexes relief might, gains newfound esteem. Japan Times; 2011. http://www.japantimes.co.jp/text/nn20110415f1.html

36. Kato $\mathrm{H}$, Asukai N. Psychological effect of rescue workers. From large-scale investigation of firefighters in the Great Hanshin-Awaji Earthquake. The Japanese Journal of Traumatic Stress. 2004;2:51-9.

37. Talmadge E. Japan mobilizes 100,000 troops for tsunami recovery Thestar. com; 2011. http://www.thestar.com/news/world/2011/03/31/japan_ mobilizes_100000_troops_for_tsunami_recovery.html

38. Alexander DA, Wells $\mathrm{A}$. Reactions of police officers to body-handling after a major disaster. A before-and-after comparison. Br J Psychiatry. 1991;159:547-55.

39. Jones N, Seddon R, Fear NT, McAllister P, Wessely S, Greenberg N Leadership, cohesion, morale, and the mental health of UK Armed Forces in Afghanistan. Psychiatry. 2012;75(1):49-59.

40. McLay RN, Deal WE, Murphy JA, Center KB, Kolkow TT, Grieger TA. On-therecord screenings versus anonymous surveys in reporting PTSD. Am J Psychiatry. 2008;165(6):775-6.

41. Goto T, Wilson JP. A review of the history of traumatic stress studies in Japan: from traumatic neurosis to PTSD. Trauma Violence Abuse. 2003:4(3):195-209.

\section{Submit your next manuscript to BioMed Central and we will help you at every step:}

- We accept pre-submission inquiries

- Our selector tool helps you to find the most relevant journal

- We provide round the clock customer support

- Convenient online submission

- Thorough peer review

- Inclusion in PubMed and all major indexing services

- Maximum visibility for your research

Submit your manuscript at www.biomedcentral.com/submit
) Biomed Central 